\section{Challenge of HIV testing in low prevalence settings}

The article on HIV testing in abortion clinics provides a compelling argument for normalising HIV testing and making it part of our general medical care. ${ }^{1}$ Similar discussions regarding approaches to HIV testing in low prevalence settings are ongoing in general practice. ${ }^{23}$

We recently reviewed the recorded HIV status of patients from countries of high HIV prevalence ( $>1 \%$ ) in our practice in Portsmouth, UK (an area with an HIV prevalence of less than $0.2 \%$ ), identifying 124 patients born in sub-Saharan African countries. ${ }^{4}$ Among these patients there were a variety of ages and ethnic groups. In $90 \%$ of these patients no HIV status was recorded.

We were then faced with a dilemma. Based on 2008 UK National Guidelines for HIV testing, HIV testing should be routinely offered to people from countries of high HIV prevalence. ${ }^{5}$ However, no further guidance is offered regarding what is meant by 'routine testing'; whether we should attempt to contact this at-risk group of patients systematically and, if so, how we should contact them?

Opportunistic testing is an option, but given that some of these patients have not consulted for a number of years could mean that some time could pass before there is an opportunity to discuss HIV testing with the potential for delayed diagnosis. We have raised awareness regarding HIV testing among our staff and patients and plan to re-audit to see whether these changes have resulted in increased testing.

In addition to people known to be from a country of high HIV prevalence ( $>1 \%)$, the guidelines outline seven other categories of patients in whom HIV testing should be routinely offered in low prevalence settings. The recommendations for low prevalence settings appear sensible, but are difficult to implement in the real world. It requires significant input in terms of staff training to identify at-risk patients, and there are issues of raising the subject of an HIV test during a consultation for a different problem. In contrast, it is relatively easy to design services providing universal screening. Although the cost-effectiveness of universal testing in low prevalence settings is still to be established, such a strategy is likely to be the most successful in identifying those currently living with HIV and unaware of their infection.

Chris Smith, MRCGP, MSc

NIHR In-Practice Fellow, Imperial College London and General Practitioner, Portsmouth, UK; smithcj1@hotmail.com

Competing interests None.

J Fam Plann Reprod Health Care 2012;38:138. doi:10.1136/fprhc-2011-100265

\section{References}

1 Bates SM. HIV testing in abortion clinics. J Fam Plann Reprod Health Care 2011;37:198-200.

2 Arkell P, Stewart E, Williams I. HIV: low prevalence is no excuse for not testing. $\mathrm{Br} J \mathrm{Gen}$ Pract 2011;61:244-245.

3 Smith C. HIV: low prevalence is no excuse for not testing. Br J Gen Pract 2011;61:436-437.

4 Health Protection Authority. Diagnosed HIV Prevalence by Strategic Health Authority (SHA) and Primary Care Trust (PCT) in England, 2009. 2009. http://www.hpa.org.uk/webc/ HPAwebFile/HPAweb_C/1228207185359 [accessed 16 December 2011].

5 British HIV Association. UK National Guidelines for HIV Testing 2008. 2008. http:// www.bhiva.org/documents/Guidelines/Testing/ GlinesHIVTest08.pdf [accessed 16 December 2011]. 